Hardie, R. M. \& Watson, J. M. Mycobacterium bovis in England and Wales: past, present and future. Epidemiol. Infect. 109, 23-33 (1992).

8. Woodroffe, R., Frost, S. D. W. \& Clifton-Hadley, R. Attempts to control tuberculosis in cattle by removing infected badgers: constraints imposed by live test sensitivity. J. Appl. Ecol. 36, 494-501 (1999).

9. Mollison, D. TB in Cattle: First Report of the Statistical Auditor on the Badger Culling Trial PB5385 (MAFF Publications, London, 2000).

10. Cresswell, W. Report of the Independent Audit of Surveying and Badger Social Group Territory Delineation Procedures in the Randomised Badger Culling Trial and MAFF's Response PB5497 (MAFF Publications, London, 2001).

11. Kirkwood, J. K. Report of the Independent Auditor on the Humaneness of the Despatch Procedures Used in the Randomised Badger Culling Trial and MAFF's Response PB5325 (MAFF Publications, London, 2000).

12. Ewbank, R. Report of the Second Independent Auditor on the Humaneness of Despatch Procedures Used in the Randomised Badger Culling Trial and Defra's Response PB8253 (Defra Publications, London, 2003).

13. Le Fevre, A. M. et al. Changes in Badger Setts Over the First Three Years of the Randomised Badger Culling Trial 〈http://www.svepm.org.uk/Posters2003/poster_files/LeFevre.pdf〉 (2003).

14. Roper, T. J. \& Lüps, P. Disruption of territorial behaviour in badgers Meles meles. Z. Säugetierkunde 58, 252-255 (1993).

15. Cheeseman, C. L., Cresswell, W. J., Harris, S. \& Mallinson, P. J. Comparison of dispersal and other movements in two badger (Meles meles) populations. Mamm. Rev. 18, 51-59 (1988).

16. Tuyttens, F. A. M., Macdonald, D. W., Rogers, L. M., Cheeseman, C. L. \& Roddam, A. W. Comparative study on the consequences of culling badgers (Meles meles) on biometrics, population dynamics and movement. J. Anim. Ecol. 69, 567-580 (2000).

17. Rogers, L. M. et al. Movement of badgers (Meles meles) in a high-density population: Individual, population and disease effects. Proc. R. Soc. Lond. B 265, 1269-1276 (1998).

18. Eves, J. A. Impact of badger removal on bovine tuberculosis in east County Offaly. Ir. Vet. J. 52, 199-203 (1999).

19. Griffin, J. M. in Selected Papers 1996 6-9 (Tuberculosis Investigation Unit, University College Dublin, 1996).

20. King, E. J., Lovell, D. J. \& Harris, S. in Advances in Vertebrate Pest Management (eds Cowan, D. P. \& Feare, C. J.) 147-161 (Filander, Fürth, 1999).

21. Doncaster, C. P. \& Woodroffe, R. Den site can determine shape and size of badger territories: implications for group-living. Oikos 66, 88-93 (1993).

Acknowledgements This study was funded and implemented by the Department of Environment, Food and Rural Affairs (DEFRA). We acknowledge the contribution made by staff of DEFRA and its associated agencies. We also wish to thank the many farmers and landowners in the trial areas who allowed the experimental treatments to operate on their land. W. T. Johnston helped prepare Fig. 3 .

Authors' contributions J.B., C.A.D., D.R.C., G.G., J.P.M., W.I.M. and R.W. constitute the Independent Scientific Group on Cattle TB, and were jointly responsible for designing and overseeing the study. Statistical analyses were carried out by D.R.C., C.A.D. and A.M.L.F. C.A.D. and R.W. drafted the manuscript, although all authors contributed to its preparation.

Competing interests statement The authors declare that they have no competing financial interests.

Correspondence and requests for materials should be addressed to C.A.D. (c.donnelly@imperial.ac.uk).

\section{Predicting distributions of}

\section{known and unknown reptile species in Madagascar}

\author{
Christopher J. Raxworthy ${ }^{1}$, Enrique Martinez-Meyer ${ }^{2}$, Ned Horning ${ }^{1}$ \\ Ronald A. Nussbaum ${ }^{3}$, Gregory E. Schneider ${ }^{3}$, \\ Miguel A. Ortega-Huerta ${ }^{2}$ \& A. Townsend Peterson ${ }^{4}$
}

${ }^{1}$ American Museum of Natural History, Central Park West at 79th Street, New York, New York 10024-5192, USA

${ }^{2}$ Instituto de Biología, Universidad Nacional Autónoma de México,

Ciudad Universitaria, Mexico City 04510, Mexico

${ }^{3}$ Museum of Zoology, University of Michigan, Ann Arbor, Michigan 48109-1079, USA

${ }^{4}$ Natural History Museum \& Biodiversity Research Center, The University of Kansas, Lawrence, Kansas 66045-2454, USA

Despite the importance of tropical biodiversity ${ }^{1}$, informative species distributional data are seldom available for biogeographical study or setting conservation priorities ${ }^{2,3}$. Modelling ecological niche distributions of species offers a potential soluion $^{4-7}$; however, the utility of old locality data from museums, and of more recent remotely sensed satellite data, remains poorly explored, especially for rapidly changing tropical landscapes. Using 29 modern data sets of environmental land coverage and 621 chameleon occurrence localities from Madagascar (historical and recent), here we demonstrate a significant ability of our niche models in predicting species distribution. At 11 recently inventoried sites, highest predictive success $(85.1 \%)$ was obtained for models based only on modern occurrence data $(74.7 \%$ and $82.8 \%$ predictive success, respectively, for pre-1978 and all data combined). Notably, these models also identified three intersecting areas of over-prediction that recently yielded seven chameleon species new to science. We conclude that ecological niche modelling using recent locality records and readily available environmental coverage data provides informative biogeographical data for poorly known tropical landscapes, and offers innovative potential for the discovery of unknown distributional areas and unknown species.

The biota of Madagascar represents a global priority for conservation owing to the island's exceptional endemic diversity and ongoing loss of natural habitats ${ }^{1}$. However, although substantial expansion of the national protected area network is anticipated ${ }^{8}$, current rates of deforestation are rapidly reducing the country's future conservation options ${ }^{9-11}$; in some regions, urgent management decisions will have to be made before detailed biological survey data become available. As a result, the ability to predict biodiversity distribution in poorly known regions of the island offers enormous potential for conservation planning. Using an evolutionary computing approach, we present predictive distribution results for 11 chameleon species, in the first application of satellite imagery to ecological distributional modelling for Madagascar.

For an initial test, with 29 environmental GIS (Geographic Information System) base layers of land cover, climate, topography and hydrology, we used random partitions of our recent post-1988 occurrence localities for building and testing ecological niche models for 11 chameleon species. Using $50 \%$ of the post-1988 occurrences to predict the remainder of the post-1988 data, this test yielded impressive results: predictions were significantly better than random for all 11 species under the 'all models predict' criteria and for 9 of the 11 species under the 'any model predicts' criteria, with an overall correct prediction success of $62.8 \%$ and $83.0 \%$ respectively (Table 1 ).

A second set of tests included pre-1978 localities $^{12,13}$ for testing models. Models based on the same random 50\% of the post-1988 occurrences as described above (for predicting post-1988) were used to predict pre-1978 occurrences. These tests produced significant results for fewer species: 4 and 5 of the 9 species, and overall prediction success was reduced to $33.1 \%$ and $63.8 \%$ (all models predict and any model predicts criteria, respectively), the reduced prediction ability probably reflecting changes in land use across Madagascar, where recent landscape data (used for modelling) less accurately reflect landscape conditions at the historical time of collecting. To investigate the influence of data density, we repeated this test with models based on $100 \%$ of the post-1988 data, and overall results were quite similar or slightly improved (models significant for 3 and 6 of the 9 species, $39.2 \%$ and $78.5 \%$ overall prediction success under the all models predict and any model predicts assumptions, ${ }^{\star}$ respectively). The final temporal partition examined the utility of pre-1978 occurrence data to predict post1988 distributions, in spite of overall low sample sizes for model building. Predictions resulted in significantly better than random for 6 and 8 of the 9 species, although overall correct prediction success was lower than the other tests $(28.0 \%$ and $57.1 \%$ under the all models predict and any model predicts criteria, respectively).

A third set of tests used data from pre-1978, post-1988 and both temporal partitions combined, for building ecological niche models that were then tested with a completely independent test data set, 


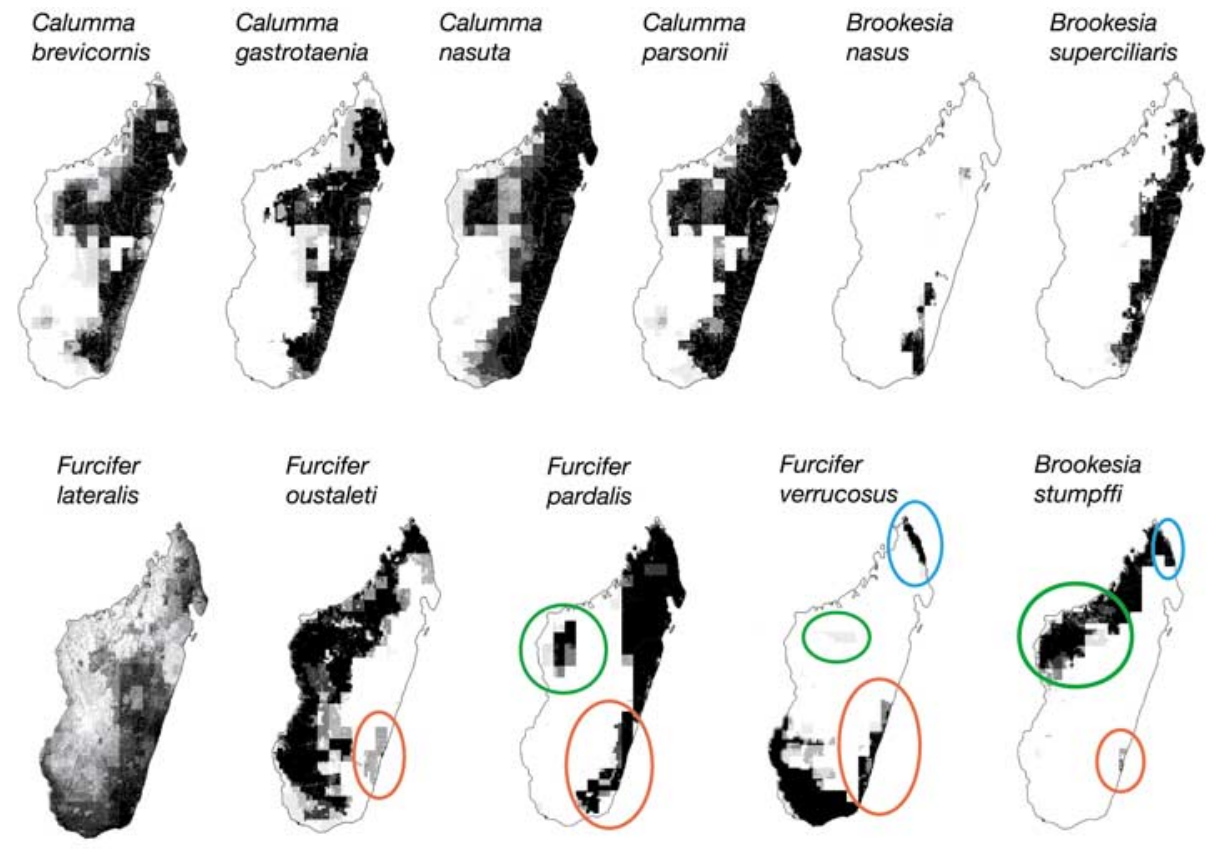

Figure 1 Ecological niche distribution models for 11 chameleon species in Madagascar. The sum of ten best-subset models is shown, with darker shading representing greater model agreement. Areas of over-prediction are circled. The intersecting over-prediction regions in the west (green) and northeast (blue) have recently yielded seven new locally endemic chameleon species; the other area in the southeast (red) remains poorly studied. The models are based on combined specimen locality data for all species except F. verrucosus and F. oustaleti (post-1988 locality data only; see Methods).

\begin{tabular}{|c|c|c|c|c|}
\hline Chameleon taxon & $\begin{array}{l}\text { Model training } \\
\text { data }(N)\end{array}$ & $\begin{array}{l}\text { Proportion of Madagascar's } \\
\text { area predicted by models }\end{array}$ & $\begin{array}{l}\text { Number of correct } \\
\text { predictions }\end{array}$ & $\begin{array}{l}\text { Statistical } \\
\text { significance }\end{array}$ \\
\hline \multicolumn{5}{|c|}{$50 \%$ post- 1988 predicts other $50 \%$ post- 1988} \\
\hline Calumma brevicornis & 14 & $0.12-0.30$ & 6 and 10 of 13 & $\star / \star$ \\
\hline Calumma gastrotaenia & 17 & $0.15-0.29$ & 12 and 16 of 16 & $\star / \star$ \\
\hline Calumma nasuta & 27 & $0.40-0.63$ & 22 and 27 of 27 & $\star / \star$ \\
\hline Calumma parsonii & 14 & $0.09-0.32$ & 5 and 10 of 14 & $\star / \star$ \\
\hline Furcifer lateralis & 42 & $0.52-0.77$ & 28 and 33 of 41 & $\star /-$ \\
\hline Furcifer pardalis & 19 & $0.15-0.30$ & 9 and 17 of 19 & $\star / \star$ \\
\hline Furcifer oustaleti & 26 & $0.39-0.69$ & 15 and 21 of 26 & $\star /-$ \\
\hline Furcifer verrucosus & 34 & $0.16-0.28$ & 26 and 29 of 34 & $\star / \star$ \\
\hline Brookesia nasus & 11 & $0.01-0.03$ & 6 and 10 of 11 & $\star / \star$ \\
\hline Brookesia stumpffi & 11 & $0.01-0.07$ & 6 and 7 of 11 & $\star / \star$ \\
\hline Brookesia superciliaris & 11 & $0.06-0.17$ & 5 and 5 of 11 & $\star / \star$ \\
\hline \multicolumn{5}{|c|}{$50 \%$ post- 1988 predicts all pre- 1978} \\
\hline Calumma brevicornis & 14 & $0.12-0.30$ & 2 and 9 of 14 & $-/ \star$ \\
\hline Calumma gastrotaenia & 17 & $0.15-0.29$ & 1 and 8 of 11 & $-/ \star$ \\
\hline Calumma nasuta & 27 & $0.40-0.63$ & 13 and 16 of 21 & $\star /-$ \\
\hline Calumma parsonii & 14 & $0.09-0.32$ & 2 and 9 of 20 & $-1-$ \\
\hline Furcifer lateralis & 42 & $0.52-0.77$ & 13 and 21 of 25 & $-1-$ \\
\hline Furcifer pardalis & 19 & $0.15-0.30$ & 4 and 7 of 12 & $-/ \star$ \\
\hline Brookesia nasus & 11 & $0.01-0.03$ & 2 and 3 of 4 & $\star / \star$ \\
\hline Brookesia stumpffi & 11 & $0.01-0.07$ & 2 and 2 of 8 & $\star /-$ \\
\hline Brookesia superciliaris & 11 & $0.06-0.17$ & 4 and 8 of 15 & $\star / \star$ \\
\hline \multicolumn{5}{|c|}{ All post-1988 predicts all pre-1978 } \\
\hline Calumma brevicornis & 27 & $0.18-0.28$ & 5 and 9 of 14 & $-/ \star$ \\
\hline Calumma gastrotaenia & 33 & $0.19-0.40$ & 2 and 7 of 11 & $-1-$ \\
\hline Calumma nasuta & 54 & $0.34-0.63$ & 13 and 16 of 21 & $\star /-$ \\
\hline Calumma parsonii & 28 & $0.23-0.49$ & 7 and 16 of 20 & $-/ \star$ \\
\hline Furcifer lateralis & 83 & $0.39-0.95$ & 9 and 24 of 25 & $-1-$ \\
\hline Furcifer pardalis & 38 & $0.21-0.38$ & 5 and 10 of 12 & $-/ \star$ \\
\hline Brookesia nasus & 22 & $0.02-0.05$ & 2 and 3 of 4 & $\star / \star$ \\
\hline Brookesia stumpffi & 22 & $0.07-0.13$ & 2 and 4 of 8 & $-/ \star$ \\
\hline Brookesia superciliaris & 22 & $0.13-0.28$ & 6 and 13 of 15 & $\star / \star$ \\
\hline \multicolumn{5}{|c|}{ All pre-1978 predicts all post- 1988} \\
\hline Calumma brevicornis & 14 & $0.18-0.29$ & 7 and 16 of 27 & $-/ \star$ \\
\hline Calumma gastrotaenia & 11 & $0.10-0.32$ & 11 and 13 of 33 & $\star / \star$ \\
\hline Calumma nasuta & 21 & $0.19-0.22$ & 19 and 29 of 54 & $\star / \star$ \\
\hline Calumma parsonii & 20 & $0.21-0.41$ & 7 and 23 of 28 & $\star / \star$ \\
\hline Furcifer lateralis & 25 & $0.34-0.76$ & 25 and 57 of 83 & $-1-$ \\
\hline Furcifer pardalis & 12 & $0.08-0.18$ & 10 and 14 of 38 & $\star / \star$ \\
\hline Brookesia nasus & 4 & $0.01-0.03$ & 3 and 12 of 22 & $\star / \star$ \\
\hline Brookesia stumpffi & 8 & $0.06-0.13$ & 1 and 8 of 22 & $-/ \star$ \\
\hline Brookesia superciliaris & 15 & $0.13-0.21$ & 9 and 16 of 22 & $\star / \star$ \\
\hline
\end{tabular}

Models are based on chameleon locality data from pre-1978 or post-1988, the former tested with data from post-1988 and the latter tested with data from both time periods. Pairs of numbers or symbols refer to statistics calculated for the 'all models predict' and 'any model predicts' criteria, respectively. *, significant prediction $(P<0.05)$; - , not significant. 
compiled from 11 other recent site inventories (42 chameleon occurrence localities; see Methods). Here, our evaluation of predictive performance was based on correct predictions of both presence and absence related to total predictions (Table 2): predictive success was $74.7 \%$ for pre- 1978 models, $85.1 \%$ for post- 1988 models and $82.8 \%$ for combined data models, with uniformly high levels of statistical significance $\left(P=3.3 \times 10^{-6}\right.$ for pre-1978, $P=1.3 \times 10^{-11}$ for post-1988, and $P=2.8 \times 10^{-10}$ for combined data models).

On the basis of these validation exercises, we conclude that ecological niche modelling of diverse natural history museum data can provide an excellent predictive understanding of reptile species' distributions, even in a region as poorly known as Madagascar. Model predictivity was better when using modern data to predict other modern data, than when using or predicting pre-1978 (historical) data. However, between temporal partitions, predictions significantly better than random were recorded for all species except Furcifer lateralis, a widely distributed species for which statistical power was low. Most tellingly, modern and historical museum occurrence information had significant predictive power in indicating where species would and would not be found during subsequent, intensive field studies. Thus, although modern data provide the best predictivity for modelling current species distribution, when modern locality data are rare or exhibit poor spatial coverage, historical data can also provide an excellent guide for understanding the distribution of biodiversity.
Model predictions, when viewed in geographical space (Fig. 1), corresponded closely with our general understanding of chameleon distributions, except that (1) primary humid forest specialists (Calumma, Brookesia) should be confined to surviving forest fragments within distributional areas, and (2) models for Furcifer pardalis, F. verrucosus, F. oustaleti and Brookesia stumpffi show three overlapping predicted areas outside known distributional areas. Because humid forest fragments can be identified using aerial photography or satellite imagery ${ }^{9-11}$ (in addition to verification on the ground), the first exception has little impact on conservation planning; instead, for deforested areas, these models provide a novel perspective concerning the reduction in forest-specialist species' distributions as a consequence of human colonization and environmental degradation. This is particularly the case for the now almost completely deforested Central High Plateau. For example, all four Calumma species show a marked and previously unknown distribution limit between the northern and southern parts of the plateau (approximately $19^{\circ} \mathrm{S}$ ), which challenges the generally accepted assumption of a single central ecoregion biota ${ }^{8}$.

Our previous work has documented the conservative nature of ecological niche evolution, which provides predictivity of distributions for closely related species ${ }^{14,15}$. For closely related allopatric species pairs, niche conservatism is manifested as areas of overprediction in each species model. Of the three intersecting areas of over-prediction mentioned above (Fig. 1), the southeastern area (between Mahanoro, Vangaindrano and Beraketa) remains largely

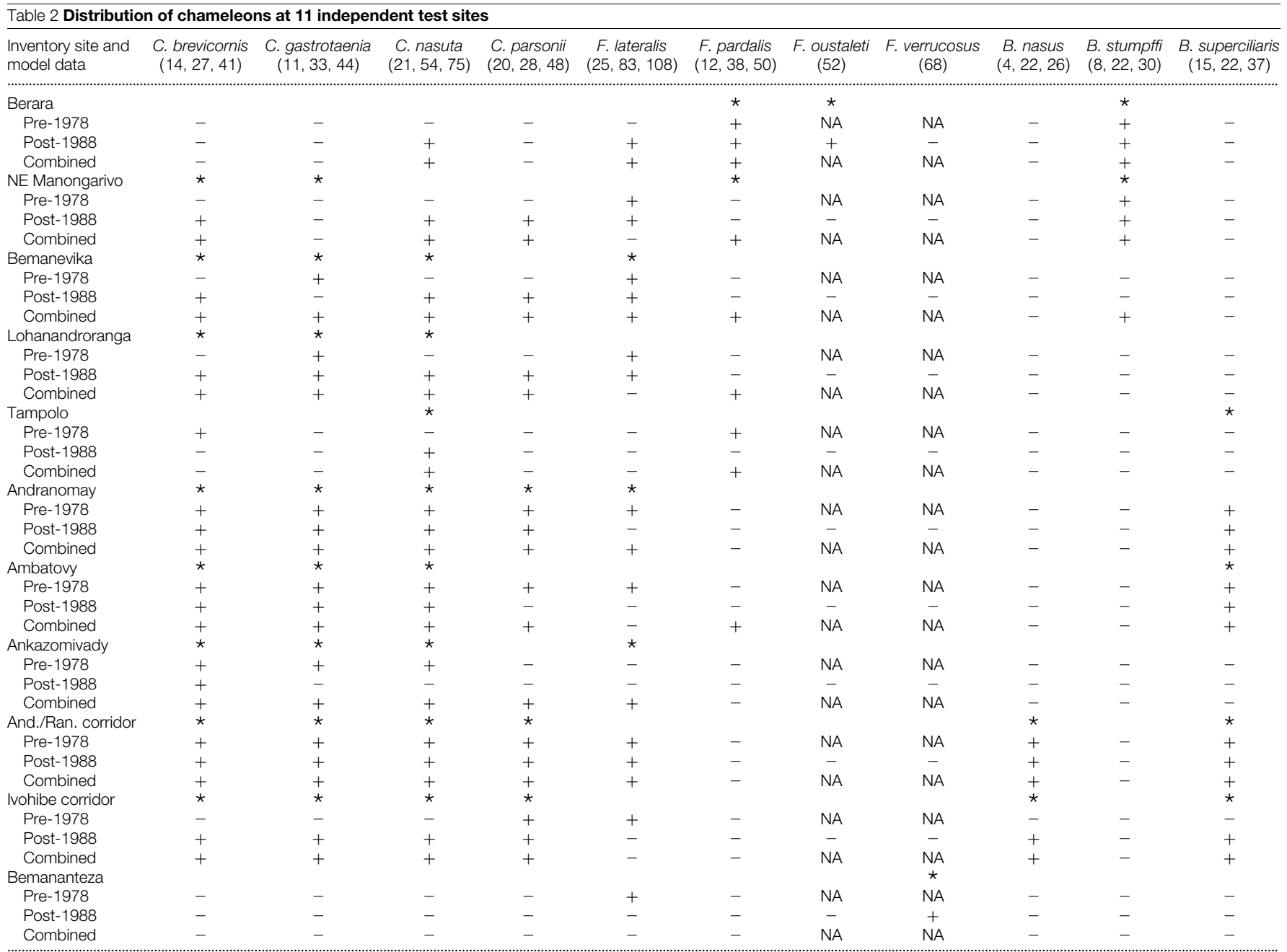

The 11 sites were recently inventoried, with predictions (presence and absence) based on ecological niche models (pre-1978, post-1988, or combined occurrence data, and the 'any model predicts' criteria). Model sample sizes (pre-1978, post-1988, combined) are given in parentheses for each species. *, recorded present during inventory; +, predicted present; -, predicted absent; NA, not applicable (see Methods); And./Ran., Andringitra-Ranomafana. 
unexplored, but we have recently surveyed the two other areas. Although neither area was previously considered rich in locally endemic Furcifer or Brookesia chameleons ${ }^{12,13}$, the western area (northern Bongolava Mountains, between Soalala, Maintirano and Tsiroanomandidy) yielded an undescribed Furcifer and an undescribed Brookesia species. The other area, in extreme northeastern Madagascar (transitional humid/dry forests between Daraina, Vohemar and Sambava), yielded five undescribed Brookesia and a possible new Furcifer species. These discoveries, of at least seven new species, sharply contrast with our results elsewhere in Madagascar: more intensive surveys at sites outside these areas of over-prediction over the same time period have produced only two other undescribed Furcifer and Brookesia chameleons. Hence, ecological niche modelling not only provides powerful predictions of species' distributions, but also offers an innovative and predictive approach to discovering heretofore unknown populations of known or unknown species.

These findings have valuable applications for identification of areas of endemism ${ }^{3}$, and consequently will also aid the development of inclusive strategies for conserving regional endemism ${ }^{16}$. In Madagascar, such a model-based evaluation of species' distributions in the context of existing reserves and protected corridors, coupled with surveys targeted on areas of predicted potentially unrecognized endemism or distribution, will provide data critical for effective future expansion of the protected area network ${ }^{8}$. Our results also highlight the continued importance of obtaining modern locality data, because of their optimal predictive performance when used with remotely sensed data. Notably, because equivalent landscape coverage data and specimen locality data are available for most other regions worldwide, this approach offers the potential for providing informative distribution data, and directing surveys to unknown populations or species, for many other poorly known and threatened environments.

\section{Methods}

\section{Species occurrence data}

Three suites of species occurrence information were used in our analyses: pre-1978 occurrences drawn from natural history museum specimens ${ }^{12,13}$ (130 unique locality $\times$ species combinations; F. verrucosus and F. oustaleti excluded due to potential taxonomic confusion), post-1988 data obtained from 1989-2002 surveys by C.J.R and R.A.N (449 unique locality $\times$ species combinations), and independent test occurrence data obtained from other recent herpetological inventories ${ }^{17-24}$ (42 unique

locality $\times$ species combinations). Post-1988 data are vouched for by specimens deposited at the American Museum of Natural History and the University of Michigan Museum of Zoology. Pre-1978 locality descriptions were converted to geographical coordinates using 1:100,000 topographic maps and gazetteers.

All Madagascar chameleon species or species/subspecies complexes ${ }^{25}$ for which $\geq 20$ occurrence localities were available from post-1988 were included: Calumma gastrotaenia (includes subspecies as recognized by refs 11 and 12), C. nasuta (C. fallax), C. parsonii (C. oshaughnessyi, C. globifer) and Brookesia superciliaris (B. therezieni), where potential synonyms are indicated in parentheses. Test data in the form of additional herpetological inventories met the following criteria: rainy season surveys (November to April) made by experienced herpetologists, designed to sample complete chameleon diversity, at sites $\geq 7 \mathrm{~km}$ from occurrence localities used in modelling. Meeting these criteria were 11 sites that included diverse primary habitats (humid to dry forests), elevation of $0-1,700 \mathrm{~m}$ and latitude of $14-23^{\circ} \mathrm{S}$ : Berara $^{17}$; northeast Manongarivo ${ }^{20}$; Tampolo $^{24}$; Andranomay ${ }^{22}$; Ankazomivady ${ }^{18}$; Andringitra-Ranomafana corridor ${ }^{21}$; Ivohibe corridor $^{23}$;

Bemananteza ${ }^{19}$; and unpublished inventory data for Bemanevika Lakes $\left(14^{\circ} 20^{\prime} \mathrm{S}\right.$, $\left.48^{\circ} 35^{\prime} \mathrm{E}\right)$, Lohanandroranga $\left(14^{\circ} 25^{\prime} \mathrm{S}, 49^{\circ} 09^{\prime} \mathrm{E}\right)$ and Ambatovy $\left(18^{\circ} 51^{\prime} \mathrm{S}, 48^{\circ} 19^{\prime} \mathrm{E}\right)$ (Raxworthy/University of Antananarivo).

\section{Ecological and environmental coverage data}

Initially, 29 GIS coverages were considered for inclusion in models. A land cover layer was derived from 17 MODIS 1-km resolution, 16-d composite, BRDF/albedo-adjusted reflectance images (MOD43B4) from November 2000 to November 2001. Unsupervised classification methods created a layer with 50 classes, subsequently grouped and edited manually into 13 land cover classes using higher resolution imagery for reference. To summarize precipitation, we used $5^{\prime}$ resolution data (1996-2001) from the NOAA Climate Prediction Center Famine Early Warning System (FEWS) (http:// edcw2ks21.cr.usgs.gov/adds/): annual minimum, maximum and mean precipitation estimates were taken from 10-d cumulative estimates provided by FEWS. Data on cloud cover, mean temperature in January, July and annually, and precipitation in January, July and annually were obtained from $\mathrm{ESRI}^{26}$; maximum, minimum, mean temperatures and mean diurnal temperature range for dry season, wet season and annually for 1961-1990 $\left(0.5^{\circ}\right.$ resolution) were obtained from ref. 27 (http://ipcc-ddc.cru.uea.ac.uk/). Finally, topographical data (elevation, slope, aspect, flow accumulation, flow direction and tendency to pool water; $1 \mathrm{~km}$ resolution) were obtained from the US Geological Survey (http://edcdaac.usgs.gov/gtopo30/hydro/). All data and coverages were re-sampled to $0.01^{\circ}$ (about $1 \mathrm{~km}$ ) resolution. Sets of geographical coverages were reduced to an optimal 25 ecological dimensions via a process of jack-knifing inclusion of dimensions in analyses and inspection of omission statistics ${ }^{28}$.

\section{Ecological niche modelling}

We used the Genetic Algorithm for Rule-set Prediction (GARP) ${ }^{4,5}$, an evolutionary computing system that has excellent capacities for delineating ecological niches and predicting geographical distributions of species $^{6,29}$. GARP niche models outline potential ecological distributions, and as such roughly map onto Hutchinson's fundamental niche concept (as opposed to the realized niche space, which takes into account the limiting effects of interactions with other species) ${ }^{29}$. GARP models were developed using a PC desktop implementation of the program (http://www.lifemapper.org/desktopgarp/).

GARP produces sets of rules delineating ecological niches by relating known occurrence points to a suite of GIS data layers describing the ecological landscape. Input points are separated into training and testing samples to permit model refinement based on independent samples of points. Simple inferential tools produce initial rules (roughly in the form of linear combinations of coverages), which serve as seeds for search and improvement in the genetic algorithm. Rules 'evolve' through an iterative process of random rule selection, evaluation, perturbation, testing, and incorporation or rejection, and the evolutionary process stops at convergence $e^{4,5}$. For each taxon, we produced 100 replicate models and a best subset of 10 models was selected based on optimal combinations of error components $\mathrm{s}^{29}$ : models that predicted $<90 \%$ of testing points were discarded, and (of the remaining models) the ten closest to the median predicted area were summed to provide a best distributional prediction.

Predictive abilities of models were evaluated using pre-1978, post-1988 and combined occurrence data, testing models with independent suites of points not included in model building (Table 1). Because sample sizes for each species were generally small, we used binomial tests to evaluate statistical significance of predictions ${ }^{30}$. Observed successes and failures were compared with random expectations based on the proportional area predicted present by the intersection of all ten or any of the ten best-subset models. For validation of models using the independent inventory data described above, a crossspecies test using a $\chi^{2} 2 \times 2$ contingency table ( 1 degree of freedom) was applied.

Received 27 August; accepted 11 November 2003; doi:10.1038/nature02205.

1. Myers, N., Mittermeier, R. A., Mittermeier, C. G., da Fonseca, G. A. B. \& Kent, J. Biodiversity hotspots for conservation priorities. Nature 403, 853-858 (2000).

2. Pimm, S. L., Russell, G. J., Gittleman, J. L. \& Brooks, T. M. The future of biodiversity. Science 269, 347-350 (1995).

3. Crisci, J. V. The voice of historical biogeography. J. Biogeogr. 28, 157-168 (2001).

4. Stockwell, D. R. B. \& Noble, I. R. Induction of sets of rules from animal distribution data: A robust and informative method of analysis. Math. Comput. Simul. 33, 385-390 (1992).

5. Stockwell, D. R. B. \& Peters, D. P. The GARP modelling system: Problems and solutions to automated spatial prediction. Int. J. Geogr. Info. Syst. 13, 143-158 (1999).

6. Peterson, A. T., Stockwell, D. R. B. \& Kluza, D. A. in Predicting Species Occurrences: Issues of Accuracy and Scale (eds Scott, J. M., Heglund, P. J. \& Morrison, M. L.) 617-623 (Island Press, Washington DC, 2002)

7. Peterson, A. T. et al. Future projections for Mexican faunas under global climate change scenarios. Nature 416, 626-629 (2002).

8. ANGAP. Plan de Gestion du Réseau National des Aires Protégées de Madagascar (Association National pour la Gestion des Aires Protégées, Antananarivo, Madagascar, 2001).

9. Green, G. M. \& Sussman, R. W. Deforestion history of the eastern rain forests of Madagascar from satellite images. Science 248, 212-215 (1990).

10. Nelson, R. \& Horning, N. AVHRR-LAC estimates of forest area in Madagascar, 1990. Int. J. Remote Sens. 14, 1463-1475 (1993).

11. Mayaux, P., Gond, V. \& Bartholomé, E. Mapping the forest-cover of Madagascar with SPOT 4-VEGETATION data. Int. J. Remote Sens. 21, 3139-3144 (2000).

12. Brygoo, E. R. Reptiles Sauriens Chamaeleontidae. Genre Chamaeleo. Faune Madagascar 33, 1-318 (1971)

13. Brygoo, E. R. Reptiles Sauriens Chamaeleontidae. Genre Brookesia et complément pour le genre Chamaeleo. Faune Madagascar 47, 1-174 (1978).

14. Peterson, A. T., Soberón, J. \& Sánchez-Cordero, V. Conservatism of ecological niches in evolutionary time. Science 285, 1265-1267 (1999).

15. Martínez-Meyer, E. Evolutionary Trends in Ecological Niches of Species. Thesis, Univ. Kansas (2002).

16. Mittermeier, R. A., Myers, N., Thomsen, J. B. \& da Fonseca, G. A. B. Biodiversity hotspots and major tropical wilderness areas: Approaches to setting conservation priorities. Conserv. Biol. 12, 516-520 (1998).

17. Andreone, F., Vences, M. \& Randrianirina, J. E. Patterns of amphibian and reptile diversity at Berera Forest (Sahamalaza Peninsula), NW Madagascar. Ital. J. Zool. (Modena) 68, 235-241 (2001).

18. Goodman, S. M. et al. Inventaire biologique de la Forêt d'Ankazomivady, Ambositra. Akon'ny Ala 24, 19-32 (1998).

19. Goodman, S. M. et al. Inventaire des vertébrés du Parc National de Tsimanampetsotsa (Toliara). Akon'ny Ala 28, 1-36 (2002).

20. Rakotomalala, D. Diversité des reptiles et amphibiens de la Réserve Spéciale de Manongarivo, Madagascar. Boissiera 59, 339-358 (2002).

21. Rakotomalala, D., Raholimavo, E., Talata, P. \& Rajeriarison, E. Les amphibiens et reptiles du Parc National de Ranomafana et de la zone forestiere le reliant au Parc National d'Andringitra. Rech. Dév. Série Sci. Biol. 17, 133-163 (2001).

22. Raselimanana, A. P. Inventaire biologique, Forêt d'Andranomay, Anjozorobe: La diversité de la faune de reptiles et d'amphibiens. Rech. Dév. Série Sci. Biol. 13, 43-59 (1998).

23. Raselimanana, A. P. Inventaire biologique de la Réserve Spéciale de Pic d'Ivohibe et du couloire 
forestier qui la relie au Parc National d'Andringitra: L’herpetofauna. Rech. Dév. Série Sci. Biol. 15, $81-97$ (1999).

24. Raselimanana, A. P., Rakotomalala, D. \& Rakotondraparany, F. Inventaire biologique de la forêt littorale de Tampolo (Fenoarivo Atsinanana). Les reptiles et amphibiens: Diversité et conservations. Rech. Dév. Série Sci. Biol. 14, 183-195 (1998).

25. Raxworthy, C. J., Forstner, M. R. J. \& Nussbaum, R. A. Chameleon radiation by oceanic dispersal. Nature 415, 784-787 (2002).

26. ESRI. ArcAtlas (Environmental Systems Research Institute, Redlands, California, 1997)

27. New, M., Hulme, M. \& Jones, P. A 1961-1990 Mean Monthly Climatology of Global Land Areas (Climatic Research Unit, University of East Anglia, Norwich, 1997).

28. Peterson, A. T. \& Cohoon, K. C. Sensitivity of distributional prediction algorithms to geographic data completeness. Ecol. Mod. 117, 159-164 (1999).

29. Anderson, R. P., Lew, D. \& Peterson, A. T. Evaluating predictive models of species' distributions: Criteria for selecting optimal models. Ecol. Mod. 162, 211-232 (2003).

30. Anderson, R. P., Laverde, M. \& Peterson, A. T. Geographical distributions of spiny pocket mice in South America: Insights from predictive models. Global Ecol. Biogeogr. 11, 131-141 (2002).

Acknowledgements We thank the Malagasy authorities and the University of Antananarivo Department of Animal Biology for their assistance. Fieldwork (C.J.R and R.A.N) was supported by Conservation International, Earthwatch, the National Geographic Society, the US National Science Foundation and the World Wide Fund for Nature. This work was supported by NASA and the Center for Biodiversity and Conservation at the American Museum of Natural History.

Competing interests statement The authors declare they have no competing financial interests.

Correspondence and requests for materials should be addressed to C.J.R (rax@amnh.org).

\section{Presynaptic induction of}

\section{heterosynaptic associative plasticity in the mammalian brain}

\section{Yann Humeau ${ }^{1}$, Hamdy Shaban ${ }^{1}$, Stephanie Bissière ${ }^{1}$ \& Andreas Lüthi ${ }^{1,2}$}

${ }^{1}$ Friedrich Miescher Institute, Maulbeerstrasse 66, CH-4058 Basel, Switzerland ${ }^{2}$ Department of Pharmacology/Neurobiology, Biozentrum, University of Basel, Klingelbergstrasse 70, CH-4056 Basel, Switzerland

The induction of associative synaptic plasticity in the mammalian central nervous system classically depends on coincident presynaptic and postsynaptic activity ${ }^{1,2}$. According to this principle, associative homosynaptic long-term potentiation (LTP) of excitatory synaptic transmission can be induced only if synaptic release occurs during postsynaptic depolarization ${ }^{1,2}$. In contrast, heterosynaptic plasticity in mammals is considered to rely on activity-independent, non-associative processes ${ }^{3-8}$. Here we describe a novel mechanism underlying the induction of associative LTP in the lateral amygdala (LA). Simultaneous activation of converging cortical and thalamic afferents specifically induced associative, $N$-methyl-D-aspartate (NMDA)-receptor-dependent LTP at cortical, but not at thalamic, inputs. Surprisingly, the induction of associative LTP at cortical inputs was completely independent of postsynaptic activity, including depolarization, postsynaptic NMDA receptor activation or an increase in postsynaptic $\mathrm{Ca}^{2+}$ concentration, and did not require network activity. LTP expression was mediated by a persistent increase in the presynaptic probability of release at cortical afferents. Our study shows the presynaptic induction and expression of heterosynaptic and associative synaptic plasticity on simultaneous activity of converging afferents. Our data indicate that input specificity of associative LTP can be determined exclusively by presynaptic properties.

Bipolar stimulating electrodes were placed on afferent fibres from the internal capsule (containing thalamic afferents) ${ }^{9-11}$ or from the external capsule (containing cortical afferents) ${ }^{12}$ in coronal slices prepared from 3-4-week-old male C57BL/6J mice (Fig. 1a). Wholecell current-clamp recordings were obtained from projection neurons in the dorsolateral portion of the LA (Fig. 1a). Lowfrequency baseline stimulation in the presence of the $\mathrm{GABA}_{\mathrm{A}}$ $(\gamma$-aminobutyric acid) receptor antagonist picrotoxin $(100 \mu \mathrm{M})$ elicited monosynaptic excitatory postsynaptic potentials (EPSPs) of similar amplitudes and slopes at both afferent inputs (thalamic, $5.6 \pm 0.4 \mathrm{mV}, \quad 1.07 \pm 0.11 \mathrm{mV} \mathrm{ms}^{-1}$; cortical, $5.7 \pm 0.4 \mathrm{mV}$, $\left.1.04 \pm 0.11 \mathrm{mV} \mathrm{ms}^{-1} ; n=13\right)$. To mimic the physiological activity of converging thalamic and cortical afferents during fear conditioning $^{13,14}$, both afferents were stimulated simultaneously for $1.5 \mathrm{~s}$ at an average frequency of $30 \mathrm{~Hz}$ using two different stimulation protocols containing Poisson-distributed stimuli ('Poisson-train'; Fig. 1b; see Methods). Simultaneous Poisson-train stimulation resulted in the induction of LTP at cortical $(151 \pm 10 \%$ of baseline, $n=13$, $P<0.01$ ), but not at thalamic, afferent synapses (98 $\pm 5 \%, n=13$, $P>0.05$; Fig. 1c). Inverting the two stimulation patterns to assess stimulation protocol-specific effects did not affect the input-specific induction of LTP at cortical input synapses (cortical, $152 \pm 16 \%$ of baseline, $n=6, P<0.05$; thalamic, $106 \pm 12 \%, n=6, P>0.05$ ). The induction of LTP was associative, in that stimulation of both the thalamic and cortical afferents was required. Stimulation of either pathway on its own did not induce LTP at cortical afferents (cortical, $106 \pm 15 \%$ of baseline, $n=6, P>0.05$; thalamic, $101 \pm 8 \%$, $n=5, P>0.05$; Fig. $1 \mathrm{~d}$ ), or at thalamic afferents (cortical, $100 \pm 8 \%$ of baseline, $n=7, P>0.05$; thalamic, $105 \pm 16 \%$, $n=5, P>0.05$; see Supplementary Information), indicating that the stimulation protocols applied were below threshold for the induction of homosynaptic ${ }^{10-12}$ and heterosynaptic LTP at cortical afferents.

Associative LTP in the hippocampus ${ }^{2}$ and the amygdala ${ }^{11,12}$ depends largely on the activation of NMDA receptors and an increase in the postsynaptic $\mathrm{Ca}^{2+}$ concentration. Accordingly, heterosynaptic, associative LTP $\left(\mathrm{LTP}_{\mathrm{HA}}\right)$ at cortical afferents could not be induced in the presence of the competitive NMDA receptor antagonist 3-(( \pm$)$-2-carboxypiperazin-4-yl)-propyl-1-phosphonic acid (CPP) at $20 \mu \mathrm{M}$ (control, $151 \pm 10 \%$ of baseline, $n=13$; CPP, $88 \pm 8 \%$ of baseline, $n=9, P>0.05$; Fig. $2 \mathrm{a}$ ). To assess whether NMDA receptor activation in conjunction with Poisson-train stimulation of cortical afferents was sufficient for the induction of LTP $_{\mathrm{HA}}$, we applied NMDA locally in the vicinity of the projection neuron from which we were recording by using a pressure application system. Whereas puff-application of NMDA in the absence of cortical afferent activity did not result in the induction of LTP (98 $\pm 4 \%$ of baseline, $n=5, P>0.05$; Fig. $2 \mathrm{~b}$ ), combining the application of NMDA with Poisson-train stimulation of cortical afferents resulted in a potentiation of cortical afferent synapses (157 $\pm 12 \%$ of baseline, $n=4, P<0.05$; Fig. $2 b)$. In contrast, pairing NMDA application with Poisson-train stimulation of thalamic afferents did not induce LTP at thalamic afferents $(99 \pm 10 \%$ of baseline, $n=3, P>0.05$; Fig. $2 \mathrm{~b}$ ).

To determine whether an increase in postsynaptic $\mathrm{Ca}^{2+}$ concentration was required for $\mathrm{LTP}_{\mathrm{HA}}$ induction we dialysed the postsynaptic neuron with the $\mathrm{Ca}^{2+}$ chelator BAPTA (10-50 mM). Surprisingly, postsynaptic dialysis with BAPTA did not prevent the induction of $\operatorname{LTP}_{\mathrm{HA}}(152 \pm 17 \%$ of baseline, $n=14$, $P<0.05$; Fig. 2c). Given that activation of NMDA receptors is required for the induction of $\mathrm{LTP}_{\mathrm{HA}}$, this finding suggests that they are not located on the postsynaptic neuron or, alternatively, that they can signal in a $\mathrm{Ca}^{2+}{ }_{\text {-independent way. To test these possibilities }}$ we dialysed the postsynaptic cell with the NMDA receptor openchannel blocker MK-801, and stimulated cortical and thalamic afferents while holding the postsynaptic cell at $+30 \mathrm{mV}$ (ref. 15). This procedure completely blocked postsynaptic NMDA receptors (Fig. 2d). However, even the complete blockade of postsynaptic NMDA receptors did not interfere with the induction of LTP $_{\mathrm{HA}}$ (134 $\pm 9 \%$ of baseline, $n=4, P<0.05$; Fig. $2 d$ ). To test whether $\mathrm{Ca}^{2+}$ signalling was required, we next incubated the slices with BAPTA-acetoxymethyl ester (BAPTA-AM; $50 \mu \mathrm{M}$ ), a membrane- 